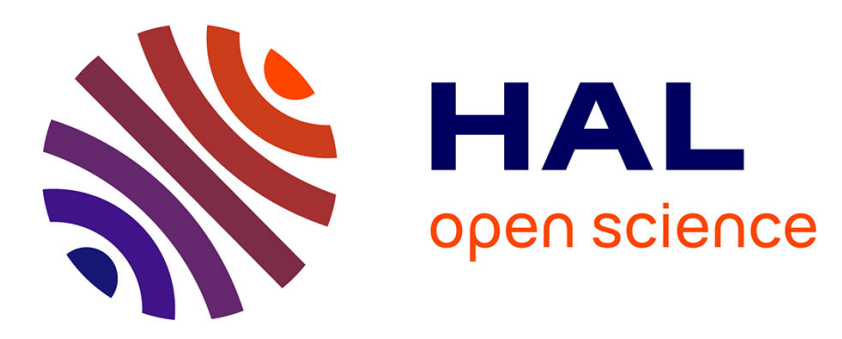

\title{
eLearning in an African Place: How 'Alien' eLearning Models Are Failing Many in Africa
}

\author{
Munyaradzi Mawere, Gertjan Van Stam
}

\section{To cite this version:}

Munyaradzi Mawere, Gertjan Van Stam. eLearning in an African Place: How 'Alien' eLearning Models Are Failing Many in Africa. 15th International Conference on Social Implications of Computers in Developing Countries (ICT4D), May 2019, Dar es Salaam, Tanzania. pp.421-432, 10.1007/978-3-03019115-3_35. hal-02281306

\section{HAL Id: hal-02281306 https://hal.inria.fr/hal-02281306}

Submitted on 9 Sep 2019

HAL is a multi-disciplinary open access archive for the deposit and dissemination of scientific research documents, whether they are published or not. The documents may come from teaching and research institutions in France or abroad, or from public or private research centers.
L'archive ouverte pluridisciplinaire HAL, est destinée au dépôt et à la diffusion de documents scientifiques de niveau recherche, publiés ou non, émanant des établissements d'enseignement et de recherche français ou étrangers, des laboratoires publics ou privés. 


\title{
eLearning in an African Place: How 'alien' eLearning Models are Failing Many in Africa
}

\author{
Munyaradzi Mawere ${ }^{1}$ and Gertjan van Stam² \\ ${ }^{1}$ Great Zimbabwe University, Masvingo, Zimbabwe \\ ${ }^{2}$ Macha Works, Zambia \\ corresponding author: gertjan@vanstam
}

\begin{abstract}
This paper discusses eLearning in contemporary times in an African place. While the paper acknowledges the importance of eLearning in that it facilitates distance learners' activities and bridges geographical gaps across the world, it notes that in convoluted environments such as those of Africa, eLearning raises a lot of critical questions, some of which are cultural, and others are ethical and epistemological. This ambiguity emerges largely because eLearning, as it is understood in Africa, comes in foreign packages. The paper argues for the decolonisation of eLearning - that external practices of eLearning, particularly those 'imposed' on Africa from Europe and North America, fail many environments in Africa. This failing is because such practices rubberstamp the long-criticised philosophy of one-size-fits-all which has been blamed for impoverishing Africa besides underestimating the potential contribution of the African continent to the global world. On this note, the paper concludes that unless we decolonise eLearning and consider the issues of sensitivity, inclusivity, and attainability, eLearning will not be palatable or at least beneficial for most in Africa.
\end{abstract}

Keywords: eLearning, Africa

\section{1 eLearning in an African place}

The received practices and theories of eLearning, mostly from the USA and Europe, may represent internationally accepted good practice yet they also embed deep political, epistemological, and cultural assumptions that may be incongruent with the cultural knowledge of users in many communities in Africa. Generally speaking, eLearning is learning that uses electronic technologies/media such as the internet, intranets and extranets [1], also referred to as educational technology. Typically, this learning takes place outside of a traditional classroom, for example, online, or blended and somehow informal as was the case in African education systems before colonialism. While this kind of learning seems worthwhile as it facilitates distance learning, provides convenience, and tries to bridge geographical gaps, in an African context, eLearning raises many questions some of which are cultural, and others are ethical and epistemological. The first question that [African] critical minds engage with as soon as they receive eLearning guidance from outside is: who designed the eLearning model and for what reason? Given the exclusion of Africa in the designing of most contemporary dominant eLearning applications, from a cultural and political perspective, this overture could be interpreted as cultural imperialism as just like what 
colonialism did to Africa. In this manner, a theory can impose cultural ethos of Europe and the Americas on Africa. The question that remains perturbing is where Africa in this whole eLearning discourse and model designing is? The second question is to what extent does e-Learning speak to the cultural and ethical concerns of Africa? This question, as is the issues raised above, is critical because any learning carries with it cultural and moral sensibilities of a people. Now, if Africa is excluded as was the case during the 1884-5 Berlin Conference when the continent was partitioned in the absence of African representatives, isn't it that imposition of eLearning on Africa tantamounts to a recolonisation of Africa? Putting it more precisely, why are most Africans remain unrepresented in the designing of theoretical and practical models that affect them directly or otherwise? The third critical question pertains to affordability - where most African rural areas are without electricity and internet connection. Is eLearning useful and practical to people living in such areas? This issue points to the fact that the imported theories of eLearning are not only culturally problematic but also morally, politically and epistemically problematic. Of course, there is a wide variety of proposed theories and practical approaches. They depend on how one approaches learning, but as noted earlier, many as they are, little comes from African perspectives.

\section{Methodology}

The authors of this paper are academics with decennia of experience in African institutes of higher education in Mozambique, South Africa, Zambia, and Zimbabwe. Through living research [2], they study how communities (of belonging, as will be shown in this paper) engage, review cultural heritage and contemporary cultural practices and paradigm switching and shifting in sectors which include, among others, education, health, and digital technology.

For this paper, the authors researched technology and African communities from an African positionality, embedded in institutes of higher education, supporting institutes in health, and rural communities. The authors tested these insights in e/merge 2018, an online festival of e-learning in Africa, 9-20 July 2018.

\section{Discordances of eLearning with African cultural expressions}

Kwame Nkrumah [3], an influential philosopher and political leader, provided an intellectual framework on social conscience founded in the African values of communal solidarity in his book consciencism. Paulo Freire (2000), the author of the widely read, Pedagogy of the Oppressed, documented his participatory practice from culture circles in North-eastern Brazil in the 1960s. However, it seems, contemporary, imported eLearning models are entirely ignorant of the various epistemai in the world.

It is necessary to pinpoint that half of the world is not connected to the Internet and that in Africa, less than a quarter of the population is using the Internet [4]. When assessing eLearning theories and practices in Africa, they need deconstruction and reconstruction as to review how they fit with features that are salient in African 
locales, at least, those that have existed over a substantial amount of time. There is identity grounding of African cultural properties that existed long while been recurrent in many African places in a way they have tended not to be elsewhere [5]. Although there are many and convoluted realities present in the pluriform African realities, from an assessment of the kind of African properties Thaddeus Metz [5] alludes to, we identify three main areas of discordance. These are paradigmatic, concern the channel, and deal with platforms and practices.

\subsection{Paradigmatic discordance}

eLearning theories rely on the epistemic grounding of the researcher and those who are being researched. It reflects the learning-perspectives adopted, mostly categorised as associationist/empiricist, cognitive, or situated [6]. These perspectives, however, are also located. Subsequently, the models and technologies that come out of them are elements of a system of behaviour. Through models and technologies, they pass from one person to another. Therefore, eLearning models and technologies represent memes.

Contemporary theories, mostly originating from outside of Africa, are said to be undergirding 'internationally accepted good practice'. Cognisant of the multiepistemic world, in the complex African environment and a multi-epistemic world, one must question from which paradigm such claims of 'good practice' have been generated. Have Africans been widely involved, and have African communities been part of the process of research, validation, development, implementation and assessment? Therefore, on which grounds is the claim of 'internationally accepted' being made?

Most conventional eLearning examples put the human learner in the centre. In such an approach, invariably the learner is set as a persona in a cultural setting that aligns with a postmodern Western urban culture that wishes to be free, with the individual being self-sufficient and self-centred. African cultures, however, put the community as the centrepiece of their worldview [7] unaligned with normative epistemologies but featuring dynamic, integrative epistemology [8]. African frameworks of how societies or nature works regard the individual to belong to a layering of communities, being an intrinsically and always connected part of such communities [9].

So far, we are not aware of eLearning that put 'the community' at the centre. Of course, in contemporary learning, there is ample recognition that education is a social activity and learning approaches based upon constructivism appear to align with life in communities, but they do not do so at the paradigmatic level. The individual learner is solidly posed at the centre. eLearning and its contemporary practices that come from a paradigm reasoning from a personal self in an atomistic universe, culminated in individualism, clash with the cultural knowledge of African students across African education [10]. African paradigms view reality from social personhood, in a universe of coherence, focusing on social cohesion and collective unity, culminating in communalism, social bonding, balancing of duties and rights, and reciprocity. It is, therefore, not strange that there appears little uptake of eLearning in African institutes [11]. 
In many parts of Africa, learning focuses on how the community learns, and from such learning, how community members gain understanding [12]. The concept of 'community of practice' and learning approaches based upon constructivism do not adequately cover this kind of meaning-making, because they focus on the individual first and upon their relationships in a community second. In many African cultural expressions, the concept of the collective surpasses the individual. These expressions pre-date the concepts of communities of practice. In many parts of Africa, an approach putting the individual as the central focus of attention is not seen as aligned with local cultures but pushing learners towards self-cultivation, individualism and, ultimately, assimilation with foreign ways of thinking. In that sense, eLearning facilitates alien ways of meaning-making and links to gaining a different way of living, e.g. set in capitalism.

\subsection{Channel discordance}

At present, eLearning is mostly proposed from 'the West' and aligns with the thinking/paradigm that created the information and communication channels (for instance, the internet) and tools (for instance mobile devices) that dominate in the global society. These models are complementary to, and intertwine with, broadband internet networking. eLearning platforms and services bank upon the ubiquitous use of computing devices and digital platforms, a setting that Dourish and Mainwaring [13] show to be inherently colonial. The apparent positioning of the use of internet telecommunications channels and (imported) computing devices as the preferred channels for eLearning is, therefore, quite problematic. This discordance can be explained as an analogy to the differences between narrowcasting and broadcasting. In line with the paradigmatic centrality of the individual, the current channels for eLearning link in with narrowcasting [14]. A community-centred paradigm, however, would need channels that would map with broadcasting. In the African society, one's membership of the community is not the result of one's 'own choice', but memberships are set by, for instance, one's birthing into a family and introductions into groupings of people in a geographical area. In the Shona language, this is signified by the reference to 'kumusha' as this touches upon issues of identity. Although constructivism regards learning as behaviour, learning as the construction of knowledge and meaning, and learning as social practice, the channel of Eurocentric Information and Communication Technologies is forcing its users into individualistic framings as the technology is geared towards establishing channels with and to the individual but does not do so for the community and with the community. For instance, there is a significant difference in using the means of the Internet on mobile devices or the use of ICT in the form of radio and call-in programs.

\subsection{Platforms and Practices}

Western knowledge systems are structured along disciplinary boundaries, while African knowledge is embodied in a transdisciplinary community, geared towards orality [12, 15]. Therefore, eLearning can only work well when the disciplines become un-disciplined, ensuring conviviality, intellectual freedom and generative 
symbiosis, in line with Ubuntu principles [16]. No wonder that the paradigm mismatch and channel mismatch have stalled eLearning praxis to be 'more of the same' in Africa. This situation calls for decolonisation of science and indeed the African academy [17] and moving the centre of conceptualisations near the community of users [18].

Current eLearning models and practices facilitate the belief in technology determination, as if the availability of computing devices and other tools and eLearning platforms will, by their sheer availability, lead to learning outcomes [19]. However, when underlying technologies do not necessarily align with technical, organisational and pedagogical systems that are current in African communities, such techniques are catering for foreign agendas, in their wake disrupting systems of knowing that have been working well. Thus, contemporary eLearning models and practices are discordant with African cultural expressions, because

- the paradigm mismatch negates necessities of belonging

- the channel mismatch negates the issue of identity

- the platforms and methods align with (digital) imperialism.

\section{$4 \quad$ African considerations influencing eLearning}

From our long-time experience in higher education and research, we noted three aspects of African culture that set boundaries for eLearning. These are 1) sensitivity, 2) inclusivity, and 3) attainability.

\subsection{Sensitivity}

Learning in an African environment is intertwined with content for specific groups and life-periods, where information transfer depending on time, place, and authority. There are great sensitivities where particular pieces of knowledge and values reside. Information can be considered sacred or subject to taboos such that they should be imparted only to specific individuals or groups of people. There are, for example, epistemic values - such as on certain rituals and rites of passages - meant explicitly for women, girls, boys, or men. In an African context, these values are not imparted in undesignated settings. eLearning is, however, not sensitive to such forms of knowledge, hence the problems when the foreign e-learning models are applied as they are in African contexts.

\subsection{Inclusivity}

There is a void of a decolonised understanding of the characteristics of eLearning that would make it useful for engaging African communities and their members and facilitate learnings sensitive to belonging, identity, and societal cohesion. The colonial history and presence of supremacy, hegemony, and domination, results in significant differences in the perception and realities of perceived value of what comes from 'the outside' and what comes from 'the inside', and with which system of thought, or reality, even paradigm, one links up [20]. Africans live with a history of having had to 
accept foreign ideas and absorbing them without critically investigating their source, history, necessity, and workability in the context of the African space. Systems of thought were introduced which instigated rebellion against the established (and working) indigenous systems of local governance and knowledge transfer. Currently, imperialistic digital systems overlay and build out these colonial systems. Subsequently, such systems sustain the continuation of the expropriation of resources out of Africa through, what we call, super-colonialism [21]. African communities are located networks of relationships and interactions, often in line with Ubuntu defining 'good behaviour'. Community instigates collective identity, local participation, and diverse support networks. Community membership and participation involve aspects of belonging, identity, participation, informedness, and associations like support networks.

eLearning is designed to result in targeted outcomes. Such a design approach imposes models or 'solutions' upon communities and learners without them being able to decide if and what should be structured and, often, without their involvement. We recognise five main cultural ingredients that African eLearning practitioners could look for to be facilitating [cf. 19].

1. Putting the community, 'being together', at the centre. Ubuntu, for instance, is a crystallisation of African philosophy in a culture that is inclusive, focusses on the contribution of everyone in its vicinity [22].

2. Focus on oral and holistic means of communication, where the aim is for embodied knowledge, a knowing that develops while sharing and discussing information involving all present while working things out together, continuously and for the good of everyone, which we dubbed 'oratio' [12, cf, 23].

3. Focus on sharing, recognising the learner as a representative of community life and its collective (embodied) human repository of knowing, dubbed 'relatio' [24].

4. A focus on the here-and-now, the ongoing experience, having a constant reestablished history and accepts an unfolding future, dubbed 'animatio' [cf. 25].

5. Respecting maturity and recognised and authorised leadership, dubbed 'dominio'.

In African eLearning, the focus would not be innovation, or 'new knowledge' per se, but is explicitly focussed on both improvisation [example in 26] and diversity.

Richard Heeks [27] positions ICT in 'ICT4D 2.0' as a transformative platform. However, if such a platform does not align with local realities, its transformation might not be development but an upsetting disruption of existing established and stable community practices. Sustaining community is an iterative process in which community members, together, continuously develop and amend what binds them, in a continually changing awareness and knowledge base that informs, shapes and triggers improvisations in community life. The main opportunities for eLearning, thus, are the engagement of community members and the provisioning of space for shared development, in the community, for the community. Without such a facility, one sets up individuals with individual knowledge which might be detrimental to the development of the community and may, ultimately, lead to expulsion or migration of such individuals. 
The knowledge creation and sharing in the communities are profoundly holistic and transdisciplinary [28]. This creation involves a complex context of relations and interactions with all kind of entities, both with humans and non-humans. These conversations are supported by a robust and multi-layered infrastructure of existing and changing technologies, like transport, communication tools, and meeting facilities. Contemporary eLearning models fall short of facilitating such a complex environment in many African communities.

\subsection{Attainability}

We must consider the qualitative and broad political, cultural, macroeconomic, and institutional drivers of eLearning and its proposed positive and potential negative consequences. Digital colonialism, also through eLearning platforms, can be sources of impoverishment and underdevelopment [29]. The so-called $21^{\text {st }}$-century skills often necessitate imported and expensive devices and the use of foreign platforms.

\section{Discussion}

If we seriously consider the issue of sensitivity, inclusivity and affordability, then eLearning could be usable in Africa, otherwise, for now, the current proposals appear fruitless packages for Africa. We are not aware of research that proves or disapproves that attention to eLearning is more effective than direct support for educators, improvement of school infrastructures and labs, and such kind of interventions, the improving existing systems [30]. Reports are suggesting either way, providing a narrative of success [31] or deficiency [32]. Andreas Schleicher of OECD's directorate for education and skills concluded cautiously: "the connections among students, computers and learning are neither simple nor hard-wired; and the real contributions ICT can make to teaching and learning have yet to be fully realised and exploited.” [33] It is clear; the verdict is not yet out and, thus, research is crucial to determine the impact of different methods on learning and their influences. In Africa, eLearning is a new realm, mostly apart from long existing processes, and invariably linked to Western notions of modernity.

The underlying and long-term effects of eLearning are yet unknown. There is a lack of longitudinal and qualitative research, embedded in African communities and sensitive to the epistemology, culture and embedding of people in Africa. Further, eLearning research seems often linked to a particular intervention or platform (e.g. Content Management Systems or Learning Management Systems) with a multitude of technologies that, in practice, have different meanings in different contexts. As all hegemonic theories and practices, eLearning needs decolonisation. Such an orientation puts communities of belonging at the centre of theory and practice. Thus, this is not the community of learners at the time of learning, but, first, putting the community that one belongs to, the complicated African citizenship at the centre [34].

What eLearning 'is' and an understanding of the undergirding theory is constructed contextually and locally. The moral grounding of currently used eLearning seems mostly (if not exclusively) framed in Western culture. As morality is a cultural 
variable [35], the ethical mismatch of eLearning models engendered through Western lenses and the use in non-Western societies result in severe dysfunctionalities. Most eLearning models proposed for Africa fall short in how they include the local perceptions of affection, loyalty, authority and spirituality, among others. The process of the creation of eLearning theory and practices, and the focus of its facilitation (e.g. towards the community instead of the individual) call for putting those being affected in the driving seat of their developments which includes in the conceptualisation of the facilities for human behaviour and learning.

Current literature on eLearning cases and tools appear to prioritise 'doing' - its inputs and outcomes - often vocalised in weaponised language as 'targets' or 'penetration'. Such descriptions and vocabulary negate its 'being' and are strongly influenced by military, gender, and technical perspectives. The resulting models, therefore, are value-laden. This concoction, in an Africa place, acts out super-colonial [21]. Therefore, eLearning theory and practice insensitive to the local, African contexts are actors, or instigator, of a social change in the direction of the researcher's and designer's motives, instead of being facilitators of an ongoing, locally validated and embedded social life.

Linking eLearning models to contextuality, both for the positionality of their origins and for the positionality of its use does not make it a form of relativism but constitute a call for discussion of the kinds of values that were involved in their conceptualisations. Drawing on the emerging understanding of African expressions of eLearning, there will be tools that give direction to the deconstruction of received guidance of eLearning. From careful thinking, we can be able to understand and, subsequently create and maintain eLearning facilities that support communities and decolonised education in African societies and beyond. Such a learning-(eco-)system is aligned with the resource availability and social cohesion in a context of inclusive and respectful accommodation of all people in African lived-lives.

The contemporary monistic approach to eLearning links in and strengthens the position of the dominant (often US-based) platforms. These platforms are closely linked to (usually US-based) institutes of Eurocentric (higher) education, perpetuating its views and neoliberal ideologies. This singular process aligns with the internationalisation of education, ushered forth by globalisation that fails to deliver social, political, administrative, distributive, cultural or ecological justice [36]. Likewise, the current framing of eLearning complicates and imposes the political, economic and cultural hegemony of the West by entrenching its power seeking and defining what knowledge gets validated and what not. This framing has many drawbacks, as diversity is challenged, like those of languages, culture, and indigenous knowledge and epistemologies - for instance, on how to interact with nature. As a result, the exploitation of the less powerful by a rent seeking elite accelerates. Current eLearning rely heavily upon the ideology of market, choice and unlimited growth. Its proposals are positioned as offerings in a market, based upon unfettered freedom, for individual choice, upon the adagio that the homo economicus knows best. The models seek the maximisation of 'educational returns' in a considered stable, efficient and just society. In this ideology of individual choice, the externalities, as presented in this discussion is delegated to be sorted through 'the market of sciences'. In the current 
dispensation, this market is colonised by Eurocentrism and (e-)realities framed by rhetoric from corporate businesses [37]. These contexts actively omit, or nudge out, unwelcome information and ways of knowing by shifting the baselines, negating that what is considered 'not helpful' for their production [38]. In the meantime, (foreign) governments and (international) corporates harvest a vast amount of data through digital educational systems and platforms, gaining knowledge of academic performance and personal backgrounds within settings where the local or national guardians or societies bear responsibilities for. The generation that grew up with computers (and dominant eLearning models and systems) think that the ecosystem in which one lives is 'normal' [39] although the systems pose significant dangers by their potential to distract, facilitate harm (e.g. bullying), and lower productivity. The de facto situation of a limited choice of ecosystems (with the current one neutralising 'other ways of knowing') represents poverty in thinking and systems conceptualisation. The result is a shrinking variety and multiplicity. Decentralisation the conceptualisation of eLearning and recognising a poly-episteme world is crucial for an eLearning transition for the field of research to be relevant (and aiding) eLearning use in many (most?) parts of Africa.

There is ample need for multiple perspectives on various purposes of eLearning in different contexts. Such is a venture to discover and formulate decolonised African expressions of eLearning. The collective action, struggle and study towards such recognition is an essential process that, by and through itself, will recreate an African identity in eLearning. This endeavour could well lead to the development of new technologies that amplify African intentions, set to support the needs and desires within African paradigms, e.g. sustaining social-cultural constructs like Ubuntu. Most probably, such a theory and practice might well be unaligned with the coloniality embedded in contemporary digital systems and platforms. They will not facilitate nor sustain the extracting of African labour for a foreign private benefit. Such an eLearning will not necessitate people to leave rural areas for the city to seek connectivity to access appropriate education. It will support education geared towards sustaining a quality of life within African communities and not set up people to have to leap beyond one's physical borders to sustain life. The alleviation of Africa's dependency on foreign platforms and the blocking the tromboning of African information - where a communication starts and ends in Africa, yet transits in an intermediate country outside of the continent - is critical for African improvisation of its life-conditions.

\section{Conclusion}

The worlds of learning and technology are both complex and diverse. In this paper, we endeavoured to show that the current rendering of these worlds in eLearning is difunctional for African settings. Significant flaws denote omitting a diversity of both worldviews and cultural practices with regards to Africa. Africa's diverse and dynamic cultural expressions centre around communities, oral communication methods, sharing, timely relations and the recognition of authority, among others. Lived-lives in Africa, set in spirituality and social belonging, and a community life 
that is always available and engaging, seem to be uncatered for by current renderings of eLearning.

Contemporary eLearning theory and practices are set within powerful and framing forces of digitisation and communication technologies. The nature of eLearning, together with the use of equipment that mesmerises, appear to put constructors of models in the position where (western) thoughts and technologies limit the view on potential 'constructs' of their implementations, as they catalyse changes not only in what we do but in how we think. This subjective effect influences the fields of understanding, linking eLearning models actively with euro- and technocentric, western narratives. This linking combines with a general ignorance of western-centric academia, especially in the field of natural sciences, of other epistemologies and of different ways of knowing. Therefore, it might well be that relatively few researchers have the critical background, knowledge base, and awareness to resist such a dominant framing that is part and parcel of a global narrative of technology solving problems. In this paper, we endeavoured to step back and assess eLearning according to its merit, or lack of it, in Africa. There is a great need for transmogrification of eLearning, which could, indeed, be surprising for western actors. Such an eLearning would 'be' in line with African ways of knowing and learning, so both knowing and learning are supported seamlessly within African cultures and established ways-ofliving in communities.

eLearning practices mostly frame its use from foreign settings. They are uninvolved with African strains of philosophies of education and technology and therefore are not reflective of how eLearning could be constructed in Africa. Therefore, contemporary eLearning theories are mostly philosophically unsatisfying and its practices too rigid to cover the vastly potential of perceptions of eLearning.

African guardians of knowledge, the African academia, has a significant task to generate awareness to fulfil the vital role in safeguarding African and indigenous knowledge. In many African places, actors have multi-vocational responsibilities. Creativity and energy exist at what imperialism considers 'the periphery'. There lies a prime source for dynamic and integrative contributions for policy development while catering for multiple worldviews, for instance, supporting students at a school, communities in the lived environment, and religious institutes in the experience of their faith.

\section{References}

1. Welsh, E., Wanberg, C., Brown, K., Simmering, M.: E-learning: emerging uses, empirical results and future directions. International Journal of Training and Development 7, 245-258 (2003).

2. van Stam, G.: Method of Research in a We-Paradigm, lessons on Living Research in Africa. In: IFIP WG 9.4 Conference, 1-3 May 2019, Dar es Salaam, Tanzania (2019).

3. Nkrumah, K.: Consciencism. New York: Monthly Review Press. (1964).

4. International Telecommunications Union: ICT facts and figures 2017. ITU, Geneva (2017).

5. Metz, T.: How the West Was One: The Western as individualist, the African as communitarian. Educational Philosophy and Theory 47, 1175-1184 (2015). 
6. Mayes, T., de Freitas, S.: Review of e-learning theories, frameworks and models. London: Joint Information Systems Committee (2004).

7. Mawere, M., Mubaya, T., van Reisen, M., van Stam, G.: Maslow's Theory of Human Motivation and its Deep Roots in Individualism: Interrogating Maslow's Applicability in Africa. In: Mawere, M., Nhemachena, A. (eds.) Theory, Knowledge, Development and Politics: What Role for the Academy in the Sustainability of Africa?, pp. 55-72. Bamenda: Langaa RPCIG (2016).

8. Bigirimana, S.: Beyond the thinking and doing dichotomy: integrating individual and institutional rationality. Kybernetes 46, 1597-1610 (2017).

9. Nyamnjoh, F.: Drinking from the Cosmic Gourd: How Amos Tutuola Can Change Our Minds. Bamenda: Langaa RPCIG (2017).

10. Mawere, M., van Stam, G.: Paradigm Clash, Imperial Methodological Epistemologies and Development in Africa: Observations from rural Zimbabwe and Zambia. In: Mawere, M., Mwanaka, T. (eds.) Development, Governance, and Democracy: A Search for Sustainable Democracy and Development in Africa, pp. 193-211. Bamenda: Langaa RPCIG (2015).

11. Aguti, J.: Capacity building for teachers: The weakest link in transforming ICT integration in education. In: e/merge 2018, Festival of elearning in Africa, 9-20 July 2018, online (2018).

12. Mawere, M., van Stam, G.: Oratio: A Framing of Knowledge in the Context of Technology and Academia. In: Mawere, M., Mubaya, T. (eds.) African Studies in the Academy. The Cornucopia of Theory, Praxis and Transformation in Africa? pp. 251-264. Bamenda: Langaa RPCIG (2017).

13. Dourish, P., Mainwaring, S.: Ubicomp’s Colonial Impulse. In: UbiComp’12, 5-8 Sep 2012, Pittsburgh (2012).

14. O’Hara, K., Stevens, D.: Inequality.com Power, Poverty and the Digital Divide. Oxford: Oneworld Publications (2006).

15. van Stam, G.: Information and Knowledge Transfer in the rural community of Macha, Zambia. The Journal of Community Informatics 9 (2013).

16. Nyamnjoh, F.: \#RHODESMUSTFALL. Nibbling at Resilient Colonialism in South Africa. Bamenda: Langaa RPCIG (2016).

17. Mawere, M., Mubaya, T. (eds.). African Studies in the Academy. The Cornucopia of Theory, Praxis and Transformation in Africa? Bamenda: Langaa RPCIG (2017).

18. Bidwell, N. Moving the centre to design social media in rural Africa. AI \& SOCIETY, Journal of Knowledge, Culture and Communication 31, 51-77 (2016).

19. van Stam, G.: Reflections: a narrative on displacement of technology and meaning in an African place. Harare, Masvingo, Macha, Tilburg: Gertjan van Stam (2017).

20. Mawere, M., Awuah-Nyamekye, S.: Between Rhetoric and Reality. The State and Use of Indigenous Knowledge in Post-Colonial Africa. Bamenda: Langaa RPCIG (2015).

21. van Stam, G.: The Coming-of-Age of Super-Colonialism. In: Mawere, M., Mubaya, T. (eds.) African Studies in the Academy. The Cornucopia of Theory, Praxis and Transformation in Africa? Bamenda: Langaa RPCIG (2017).

22. Mawere, M., van Stam, G.: Ubuntu/Unhu as Communal Love: Critical Reflections on the Sociology of Ubuntu and Communal Life in sub-Saharan Africa. In: 
Mawere, M., Marongwe, N. (eds.) Violence, Politics and Conflict Management in Africa: Envisioning Transformation, Peace and Unity in the Twenty-First Century, pp. 287-304. Bamenda: Langaa RPCIG (2016).

23. Bigirimana, S.: Patterns of Human Knowing in the Information Society. A Philosophical Study of the Epistemological Implications of the Information Revolution. Ruprecht-Karls-University, Heidelberg (2011).

24. Sheneberger, K., van Stam, G.: Relatio: An Examination of the Relational Dimension of Resource Allocation. Economics and Finance Review 1, 26-33 (2011).

25. Bidwell, N., Reitmaier, T., Rey-Moreno, C., Roro, Z., Siya, M., Dlutu-Siya, B.: Timely Relations in Rural Africa. In: Proceedings of the 12th International Conference of the IFIP 9.4 Working Group on Social Implications of Computers in Development Countries, 19-22 May 2013, Ocho Rios, Jamaica (2013).

26. MoHCC: The National Health Strategy for Zimbabwe, 2016-2020. Equity and Quality in Health: Leaving No One Behind. Ministry of Health and Child Care, Government of Republic of Zimbabwe, Harare (2016).

27. Heeks, R.: ICT4D 2.0: The next phase of applying ICT for international development. Computer 41, 26-31 (2008).

28. Du Plessis, H., Sehume, J., Martin, L.: The Concept and Application of Transdisciplinarity in Intellectual Discourse and Research. Mapungubwe Institute for Strategic Reflection, Johannesburg (2013).

29. Kwet, M.: Break the hold of digital colonialism. Mail \& Guardian (2018).

30. van Stam, G.: Preparing the Next Generation of Teachers. In: National Dialogue on ICT for Education for Sustainable Development, 11-14 March 2014, Juliasdale, Zimbabwe (2014).

31. Chen, M.: Education Nation: six leading edges of innovation in our schools. Jossey-Bass, San Francisco (2010).

32. Biagi, F., Loi, M.: ICT and Learning: Results from Pisa 2009. European Commission, Luxembourgh (2012).

33. OECD: Students, Computers and Learning. Making the Connection. OECD Publishing, Pisa (2015).

34. Nyamnjoh, F.: From Bounded to Flexible Citizenship: Lessons from Africa. Citizenship Studies 11, 1-11 (2007).

35. Haidt, J.: The New Synthesis in Moral Psychology. Science 316, 998-1002 (2007).

36. Olivier, B.: Ethical Challenges Regarding Globalization of Higher Education. US-China Education Review 6, 816-823 (2011).

37. UNCTAD: Trade and Development Report 2018. Power, Platforms and the Free Trade Delusion. United Nations (2018).

38. Mansell, R.: Our digitally mediated society. In: Büllesbach, D., Cillero, M., Stolz, L. (eds.) European Alternatives: Shifting Baselines of Europe, pp. 119128. Transcript Verlag, Bielefeld (2017).

39. Ndemo, B., Weiss, T.: Digital Kenya. An Entrepreneurial Revolution in the Making. Palgrave Macmillan, London (2017). 